\title{
McKellar General Hospital, Thunder Bay, Ontario CERTIFIED ANAESTHETIST
}

Situated on the Northern Shore of Lake Superior, fully accredited 321 bed hospital with an 11 bed ICU. Regional Trauma Centre \& Base Hospital supplying Tertiary care to all North West Ontario.

A Certified Anaesthetist is required to join 5 other Anaesthetists. Fee for service, established pain clinic.

Applicants should have an interest in critical care. Applicant will be eligible for Underserviced Area grant. Thunder Bay population 120,000. Excellent range of Summer \& Winter Recreational Facilities close to City. Exceptional air service to Toronto. Affordable Housing.

Send C.V.\& 3 Ref. to:

Dr. J. Middleton, Department of Anaesthesia, McKellar General Hospital 325 South Archibald Street, Thunder Bay, Ontario P7E 1 G6

Phone (807) 343-7123

\section{ANAESTHETIC OPPORTUNITIES IN AUSTRALIA STAFF ANAESTHETISTS / THE GEELONG HOSPITAL}

The Geelong Hospital is an acule general teaching hospital of the University of Melboume, with a full range of surgical specialties. A Professorial Department of Surgery has been established, and the development of cardiac surgery is planned.

The Hospital has a department staffed with full-time and visiting anaesthetists. The development of research and teaching activities is encouraged. The throughput of surgical patients is being increased and anaesthetists with high quality clinical skills, as well as the motivation to contribute to a teaching hospital department, are encouraged to apply for these positions. Initial appointments of one year, with the opportunity for renewal, will be offered.

Anaesthetists with FRCPC are eligible for specialist recognition in anaesthesia in Australia, subject to approval of training.

The Hospital will assist successful applicants in applying for immigration permits, registration and specialist recognition. Terms and conditions of employment are attraclive, and assistance will be provided with travel and accommodation expenses.

Geelong is the provincial capital of Victoria (popn. 200,000) and offers excellent recreational, educational and cultural facilities. Geelong is the gateway to the Bellarine Peninsula and the west coast of Vicloria, both areas noted for their fine surf beaches and tourist attractions.

Further information may be obtained from the Director of Anaesthesia, Dr Keith Cronin, on Australia +61-52-267333.

Applicants should send a curriculum vitae containing a recent photo, plus names, addresses and telephone numbers and facsimile numbers of three medical referees to: Dr. Heather L. Wellington, Director of Medical Services

The Geelong Hospital, PO Box 281, Geelong, Victoria, Australia 3220

Telephone inquiries are welcome on $+61-52-267593$, and applications may be sent by facsimile on $+61-52-213429$.

\section{INDEX TO ADVERTISERS}

Hoffman-La Roche Limited.

(PAGE) PRESCRIBING INFO. (PAGE)

Janssen Pharmaceutica

XI, OUTSIDE BACK COVER $\mathrm{XXIII,} \mathrm{XXIV}$

Ohmeda INSIDE BACK COVER

Organon (1) $x \times y$

Wellcome Medical Division/

Burroughs Wellcome Inc. INSIDE FRONT COVER $x \dot{x}, x x I$ Zeneca Pharma VIII, IX, XII, XIII XVII, XVIII, XIX

\section{CLASSIFIED ADVERTISING}

Anaesthesia and Intensive Care

Canadian Anaesthetists' Society . vI, $x, x I v, x v$

Classified Advertising and Meetings
$X V I, X X V I I, x X V I I I$

168
Geelong Hospital ...................................................

IARS ............................................................ VII

McKellar General Hospital ....................................xx

University of Toronto Press Incorporated ............xxIv 